\title{
Prevention of Chloride-induced Corrosion Damage to Bridges
}

\author{
S. D. CRAMER, B. S. COVINO, Jr., S. J. BULLARD, G. R. HOLCOMB, J. H. RUSSELL, M. ZIOMEK-MOROZ, \\ Y. P. VIRMANI, ${ }^{1)}$ J. T. BUTLER, ${ }^{2)}$ F. J. NELSON ${ }^{3)}$ and N. G. THOMPSON ${ }^{4)}$ \\ Albany Research Center, USDOE, Albany OR 97321 USA. E-mail: cramer@alrc.doe.gov \\ 1) Turner-Fairbank Highway \\ Research Center, FHWA, USDOT, McLean VA 22101-2296 USA. \\ 3) Oregon Department of Transportation, Salem OR 97310 USA. \\ 2) Joseph T. Butler, Inc., Wadsworth OH 44282 USA. \\ 4) CC Technologies, Dublin OH 43016-8761 USA.
}

(Received on May 24, 2002; accepted in final form on August 19, 2002)

\begin{abstract}
The annual direct cost of bridge infrastructure corrosion to the U.S. economy is estimated at $\$ 8.3$ billion, with indirect costs approximately 10 times higher. Of the approximately 600000 bridges in the U.S., between $15 \%$ and $20 \%$ are listed as "structurally deficient", frequently due to corrosion damage. Five technologies are presented for reducing the cost of chloride-induced corrosion damage: (1) conductive coating anodes for cathodic protection of existing reinforce concrete bridges, (2) epoxy-coated rebar (ECR), (3) stainless steel rebar, and (4) high-performance concrete for extending the service life of new structures, and (5) metalizing to provide economical, long-term corrosion protection of steel bridges. Conductive coating anodes and stainless steel rebar represent ongoing work by the Oregon Department of Transportation with final verdicts not expected for years. The ECR and metalizing technology have longer track records and are better established in the bridge construction and protection industry. Application of these technologies is guided by a thorough understanding of their performance, of characteristics of the bridge and its environment, and of the results that are sought.
\end{abstract}

KEY WORDS: cost of corrosion; bridges; reinforced concrete; steel; epoxy-coated rebar; stainless steel; corrosion; chloride; anodes; cathodic protection; microsilica concrete; metalizing; thermal spray.

According to the National Bridge Inventory Database, there are approximately 600000 bridges in the United States. ${ }^{1)}$ Half of these were built between 1950 and 1994. The vast majority built since 1950 are reinforced-concrete (RC) and steel bridges, both of which can undergo significant deterioration due to chloride-induced corrosion. During the period 1992-1999, between $15 \%$ and $20 \%$ of all bridges in the US were listed as "structurally deficient", that is, they can no longer sustain the loads for which they were designed. ${ }^{2,3)}$ As older bridges are replaced or rehabilitated, there is a trend of decreasing number and percentage of structurally deficient bridges while, over the 1992-1999 period, the number of bridges in the inventory rose by about 13000 . The 1998 bridge inventory data are presented in more detail in Table 1. ${ }^{1-3)}$ Of the three predominant materials of construction, the highest percentage of structurally deficient bridges were steel, followed by conventional RC and pre-stressed concrete.

The cost to replace aging bridges increased by $12 \%$ from 1995 to 1999. In addition, there was a significant increase in the required maintenance. Many pre-stressed concrete bridges will require maintenance in the next 10 to 30 years. Significant maintenance, repair, rehabilitation, and replacement activities for the nation's highway bridge infrastructure are foreseen over the next few decades before current construction practices reverse the trend.

A recent Federal Highway Administration (FHWA) report by Koch et al. ${ }^{3)}$ estimated the direct cost of corrosion to the entire U.S. economy to be $\$ 276$ billion/y for 1998 , Table 2. The direct cost of corrosion for bridge infrastructure was $\$ 8.3$ billion $/ y$. ${ }^{3)}$ The total estimated cost to replace structurally deficient bridges was $\$ 29.3$ billion, annualized over a 10 year period to be $\$ 3.8$ billion $/ y$. The estimated annual direct life-cycle corrosion costs for non-deficient bridges, including construction, maintenance, patching, rehabilitation, cathodic protection, and cost of capital, are: (1) bridge decks - $\$ 1.1$ to $\$ 2.9$ billion/y; (2) substructure and superstructure (minus decks) $\$ \$ 1.1$ to $\$ 2.9$ billion $/ \mathrm{y}$; (3) steel bridge maintenance painting $-\$ 0.5$ billion/y. For "average" bridges using somewhat less than best maintenance practices this yields an estimated annual direct life-cycle cost of $\$ 4.5$ billion $/ y$.

Annual indirect bridge infrastructure corrosion costs due to traffic delays and lost productivity are estimated to be more than 10 times the $\$ 8.3$ billion direct cost of corrosion. This is in sharp contrast to the total indirect cost of corrosion to the U.S. economy, estimated to be equal to the direct cost. $^{3)}$ In other words, the economic penalty of bridge infrastructure corrosion is proportionally much higher than the impact of corrosion on all industry sectors considered together.

This paper addresses five technologies for reducing the cost of chloride-induced corrosion to bridge infrastructure: (1) conductive coating anodes for cathodic protection (CP) on existing RC bridges; (2) epoxy-coated rebar (ECR) to extend RC bridge service life; (3) stainless steel rebar and 
Table 1. Structurally deficient bridges in 1998 based on material of construction. ${ }^{1-3)}$

\begin{tabular}{lccccc}
\hline & $\begin{array}{c}\text { CONVENTIONAL } \\
\text { RC }\end{array}$ & $\begin{array}{c}\text { PRESTRESSED } \\
\text { CONCRETE }\end{array}$ & STEEL & OTHER & TOTAL \\
\hline Bridges in Inventory & 235,151 & 107,666 & 200,202 & 40,395 & 583,414 \\
Structurally Deficient & 21,164 & 3,230 & 54,054 & 14,671 & 93,119 \\
\% Deficient & 9 & 3 & 27 & 36 & 16 \\
\hline
\end{tabular}

Table 2. 1998 Cost of Corrosion by Sector. ${ }^{3)}$

\begin{tabular}{lrr}
\hline Infrastructure & $16.4 \%$ & $\$ 22.6$ billion/y \\
$\bullet$ bridge infrastructure & $6.0 \%$ & $\$ 8.3$ billion/y \\
Government & $20.1 \%$ & $\$ 20.1$ billion/y \\
Production and Manufacturing & $17.6 \%$ & $\$ 17.6$ billion/y \\
Transportation & $29.7 \%$ & $\$ 29.7$ billion/y \\
Utilities & $47.9 \%$ & $\$ 47.9$ billion/y \\
\hline \multicolumn{1}{c}{ Total } & $100 \%$ & $\$ 137.9$ billion/y \\
\multicolumn{1}{l}{ Total extrapolated to entire US economy } & $\$ 275.7$ billion/y \\
\hline
\end{tabular}

(4) high performance concrete to produce economical $120+$ year bridges; and (5) metalizing for economical, long-service coatings for steel bridges. The sections on conductive coating anodes, stainless steel rebar, and high performance concrete are based extensively on research conducted with the Oregon Department of Transportation (DOT). Although other technologies exist for reducing chloride-induced corrosion damage in existing and new bridges, they will not be addressed in this paper.

\section{Existing RC Bridges in Severe Environments}

Chloride-induced corrosion damage develops in RC bridges when salt diffuses into the concrete, raising the salt concentration at the reinforcing bar-concrete interface above a corrosion initiation threshold level, about $0.74 \mathrm{~kg}$ $\mathrm{Cl} / \mathrm{m}^{3}$ for black steel bar. ${ }^{4)}$ The passive film normally present on the reinforcing bar breaks down above this concentration, reducing the $\mathrm{pH}$, and then initiating corrosion of the steel. The iron oxide reaction products formed by corrosion are substantially higher in volume than the iron consumed by corrosion, leading to tensile forces that crack the concrete, causing delamination of the cover concrete, and structural deterioration of the bridge. Cathodic protection is one of the most effective means for controlling corrosion damage in RC bridges.

Oregon DOT (as well as the Florida and Alaska DOT's) uses conductive coating anodes in $\mathrm{CP}$ systems on $\mathrm{RC}$ bridges because they are less expensive to install than embedded anodes, provide better distribution of current to the rebar, and preserve architectural detail on historic coastal bridges. Total installed conductive coating anode area in Oregon is $81000 \mathrm{~m}^{2}$. Most of this area uses thermalsprayed (TS) zinc anodes. ${ }^{5)}$ Other anodes used are TS titanium, ${ }^{6)}$ TS Al-Zn-In, ${ }^{7)}$ zinc(Zn)-hydrogel, ${ }^{7)}$ and solventbased acrylic carbon paint. ${ }^{8)}$ Acidification of the anodeconcrete interface by anode reaction products may affect the performance and service life of these anodes. In Oregon, TS zinc anodes have been used for 10 years and are expected to have a 25 -year service life base on bond strength. In a limited application, the carbon paint anode has been used for over 15 years and performed well.

\subsection{Rehabilitation and Surface Preparation}

Rehabilitation of Oregon's coastal bridge prior to in- stalling a conductive coating anode CP system, regardless of the specific anode material, includes removal of cracked and delaminated concrete, replacement of reinforcing bar with more than $50 \%$ section loss, sandblasting exposed reinforcing bar and concrete to remove rust and loose concrete, applying patch concrete to restore the bridge to roughly original structural specifications and, in the case of historic bridges, to their original surface detail and appearance. ${ }^{9)}$ Surface preparation includes light sandblasting of the concrete to remove the laitance layer and loose concrete, and to produce a medium sandpaper surface texture without overly exposing the aggregate (which leads to polishing the aggregate and reduces anode bond strength). All structural steel in a CP zone is electrically tied together to provide electrical continuity. "Tramp" steel pieces, i.e, nails, wires, benches, in the concrete that could short the reinforcing bar to the anode on the concrete surface are removed prior to or during application of the anode. If the reinforcing bar (cathode) and anode become shorted during impressed current cathodic protection (ICCP) service, efforts are made to locate and remove the short. Otherwise, the $\mathrm{CP}$ zone is converted to a sacrificial anode cathodic protection (SACP) zone.

Specific coating anodes used in Oregon are discussed below grouped by the type of CP system used: ICCP or SACP.

\subsection{ICCP Anodes}

Conductive coating anode ICCP systems on the Oregon coast are typically operated under current control at a current density of $2.2 \mathrm{~mA} / \mathrm{m}^{2}\left(0.2 \mathrm{~mA} / \mathrm{ft}^{2}\right)$ based on anode area (as opposed to rebar area). ${ }^{5)}$ Protection of the reinforcing bar is determined by periodic depolarization measurements followed by current density adjustments as necessary to meet the $100 \mathrm{mV}$ depolarization criteria.

\subsubsection{TS Zinc Anode}

TS zinc anodes are applied to coastal RC bridges using the twin-wire arc spray process, which yields high production rates with $4.8 \mathrm{~mm}$ (3/16 inch) diameter wire. ${ }^{5)}$ Typical thermal-spray parameters are given in Table 3 for zinc wire in 3.2 and $4.8 \mathrm{~mm}$ (1/8 and $3 / 16$ inch) wire diameters. ${ }^{10)}$ The $4.8 \mathrm{~mm}$ diameter wire is typically used because of higher application rates. The atomizing gas is compressed air at $0.62-0.79 \mathrm{MPa}(90-110 \mathrm{psi})$; spray orientation is normal to the sprayed surface at a distance of 15-23 cm (6-9 inches). Multiple passes in an $\mathrm{X}-\mathrm{Y}$ pattern are used to build up coating thickness. TS anodes are formed by the fine spray of molten metal created in the electric arc and accelerated to the concrete surface by the atomizing gas. There the spray is deposited, freezing in place as "splats", and forming a dense but somewhat porous structure. Preheating of the concrete is not necessary prior to spraying and does not benefit the long-term adhesion of the anode. However, the concrete must be clean and dry and the workspace 
Table 3. Twin-wire arc thermal spray parameters for zinc. ${ }^{10)}$

\begin{tabular}{|c|c|c|c|c|c|c|c|c|c|c|c|c|}
\hline \multirow[t]{2}{*}{ Wire type } & \multirow{2}{*}{$\begin{array}{l}\text { Wire } \\
\text { size } \\
\text { inch }\end{array}$} & \multirow[t]{2}{*}{$\begin{array}{c}\mathrm{DC} \\
\text { amps }\end{array}$} & \multirow[t]{2}{*}{$\begin{array}{c}\mathrm{DC} \\
\text { volts }\end{array}$} & \multicolumn{2}{|c|}{$\begin{array}{l}\text { Spray } \\
\text { rate }\end{array}$} & \multirow{2}{*}{$\begin{array}{c}\text { Deposition } \\
\text { efficiency } \\
\%\end{array}$} & \multicolumn{2}{|c|}{$\begin{array}{l}\text { Deposition } \\
\text { rate }\end{array}$} & \multicolumn{2}{|c|}{ Wire density } & \multicolumn{2}{|c|}{$\begin{array}{l}\text { Deposition volume } \\
\text { rate }\end{array}$} \\
\hline & & & & $\mathrm{lb} / \mathrm{hr}$ & $\mathrm{kg} / \mathrm{hr}$ & & $\mathrm{lb} / \mathrm{hr}$ & $\mathrm{kg} / \mathrm{hr}$ & $\mathrm{lb} / \mathrm{in}^{3}$ & $\mathrm{~g} / \mathrm{cm}^{3}$ & $\mathrm{in}^{3} / \mathrm{hr}$ & $\mathrm{cm}^{3} / \mathrm{hr}$ \\
\hline Zinc & $1 / 8$ & 250 & 27 & 57.2 & 25.9 & $58.0 \%$ & 33.2 & 15.0 & 0.25 & 7.14 & 132.7 & 2180 \\
\hline Zinc & $1 / 8$ & 350 & 27 & 83.0 & 37.6 & $58.0 \%$ & 48.1 & 21.8 & 0.25 & 7.14 & 192.6 & 3160 \\
\hline Zinc & $1 / 8$ & 400 & 27 & 91.0 & 41.2 & $58.0 \%$ & 52.8 & 23.9 & 0.25 & 7.14 & 211.1 & 3460 \\
\hline Zinc & $1 / 8$ & 450 & 27 & 102.0 & 46.2 & $53.6 \%$ & 54.7 & 24.8 & 0.25 & 7.14 & 218.7 & 3590 \\
\hline Zinc & $1 / 8$ & 600 & 27 & 129.0 & 58.4 & $50.0 \%$ & 64.5 & 29.2 & 0.25 & 7.14 & 258.0 & 4230 \\
\hline Zinc & $3 / 16$ & 250 & 27 & 84.7 & 38.4 & $61.8 \%$ & 52.3 & 23.7 & 0.25 & 7.14 & 209.4 & 3430 \\
\hline Zinc & $3 / 16$ & 350 & 27 & 113.0 & 51.2 & $64.8 \%$ & 73.2 & 33.2 & 0.25 & 7.14 & 292.9 & 4800 \\
\hline Zinc & $3 / 16$ & 400 & 27 & 124.0 & 56.2 & $64.0 \%$ & 79.4 & 36.0 & 0.25 & 7.14 & 317.4 & 5200 \\
\hline Zinc & $3 / 16$ & 450 & 27 & 135.1 & 61.2 & $67.4 \%$ & 91.1 & 41.2 & 0.25 & 7.14 & 364.2 & 5970 \\
\hline Zinc & $3 / 16$ & 600 & 27 & 166.0 & 75.2 & $68.0 \%$ & 112.9 & 51.1 & 0.25 & 7.14 & 451.5 & 7400 \\
\hline
\end{tabular}

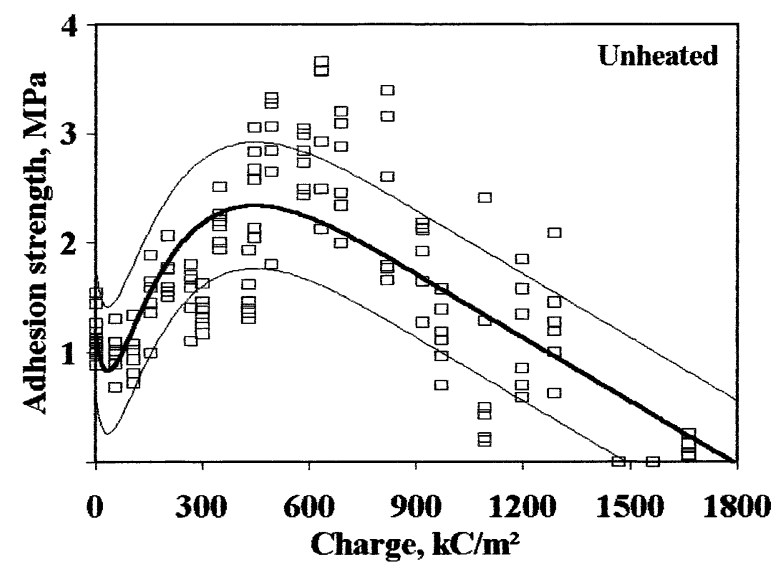

Fig. 1. Bond strength of the TS Zn anode on periodically-wetted unheated concrete slabs versus electrochemical age $\left(1 \mathrm{yr}=67.9 \mathrm{kC} / \mathrm{m}^{2}\right)$. The heavy solid line is the best fit of the data, and the two lines paralleling this line are the $70 \%$ confidence limits. 5 )

should have a relative humidity of $60 \%$ or less. ${ }^{9)}$ Present Oregon DOT acceptance criteria for thermal-sprayed $\mathrm{Zn}$ anodes on coastal RC bridges are: a coating thickness of 0.37 $\mathrm{mm}(14.7 \mathrm{mil})$, and anode bond strength of $0.34 \mathrm{MPa}(50$ psi).

The TS zinc anode is consumable, leading to acidification of the anode-concrete interface (with the $\mathrm{pH}$ decreasing from roughly 13 to 7 ), and the formation of zinc minerals that reduce the long-term anode bond strength and increase the CP circuit resistance in ICCP service. ${ }^{5)}$ In accelerated laboratory studies, bond strength for periodicallywetted anodes decreased from 4.0 MPa (580 psi) to $0.1 \mathrm{MPa}$ (15 psi) over the equivalent of 27 years service at the Oregon DOT coastal CP current density, Fig. 1. Referring to Fig. 1, the charge (electrochemical age) passed across the zinc anode-concrete interface is directly proportional to the time the anode is in service. At the current density Oregon DOT typically operates coastal bridge ICCP systems, 2.2 $\mathrm{mA} / \mathrm{m}^{2}$, one calendar year is equivalent to a charge of 67.9 $\mathrm{kC} / \mathrm{m}^{2}$. Note that in-service performance of the anodes may differ from that determined in accelerated laboratory studies since transport processes in concrete cannot be accelerated in the same way as anode electrochemical reactions. Accelerated laboratory studies were conducted to provide guidance on the long-term performance of conductive coat- ing anodes.

Moisture at the anode-concrete interface had a strong effect on anode performance; drier conditions substantially decreased anode service life based on bond strength. ${ }^{5)}$ Application of humectants (moisture attracting chemicals such as $\mathrm{LiBr}$ and $\mathrm{LiNO}_{3}$ ) can increase moisture levels at the anode. ${ }^{11)}$ Increasing circuit resistance may also be a factor in determining anode service and, in fact, limited the original TS zinc anode on the Richmond-San Rafael Bridge (CA) to 13 years service before operating voltages exceeded levels acceptable to the California Department of Transportation. 5) This has not been the case in Oregon, where anode operating voltages are still reasonably low after up to 11 years service. Some delamination of the anode has been observed at isolated locations over this same period and is thought to be caused by poor surface preparation prior to anode installation and anode thickness substantially greater than specified.

\subsubsection{Cobalt-catalyzed TS Titanium Anode}

The cobalt-catalyzed TS titanium anode is applied in the same way as the zinc anode using the twin-wire arc-spray process, but at a higher voltage. ${ }^{6}$ It is somewhat more difficult to apply than zinc because the wire is stiffer, wear rates on the spray gun tips are higher, and stability of the arc is more critical. The anode is applied to a thickness of 0.10 $0.15 \mathrm{~mm}$ (4-6 mil). The anode is non-consumable, based on the oxidation of moisture on the anode, and leads to acidification of the anode-concrete interface in ICCP service with the $\mathrm{pH}$ decreasing from roughly 13 to 7 . It is catalyzed by a cobalt nitrate-amine complex applied as an aqueous solution. Despite the reactivity of molten $\mathrm{Ti}$ in the atmosphere, the anode contains $88 \mathrm{wt} \% \mathrm{Ti}$, present as $\alpha$-Ti containing interstitial nitrogen, $\gamma$-TiO, and possibly TiN. Nitrogen atomization rather than compressed air atomization produces anodes with more uniform chemistry, less internal cracking, and lower resistivity. In accelerated laboratory studies, bond strength for periodically wetted anodes decreased from 1.2 $\mathrm{MPa}$ (175 psi) to $0.3 \mathrm{MPa}$ ( $40 \mathrm{psi}$ ) after the equivalent of 23 years service at the Oregon DOT coastal CP current density. Circuit resistance remained unchanged over this period. Unlike zinc anodes, anode operation is relatively insensitive to moisture in the environment, remaining stable from 30 to $100 \%$ relative humidity, Fig. 2. Evidently sufficient moisture is supplied to the catalyzed anode surface 


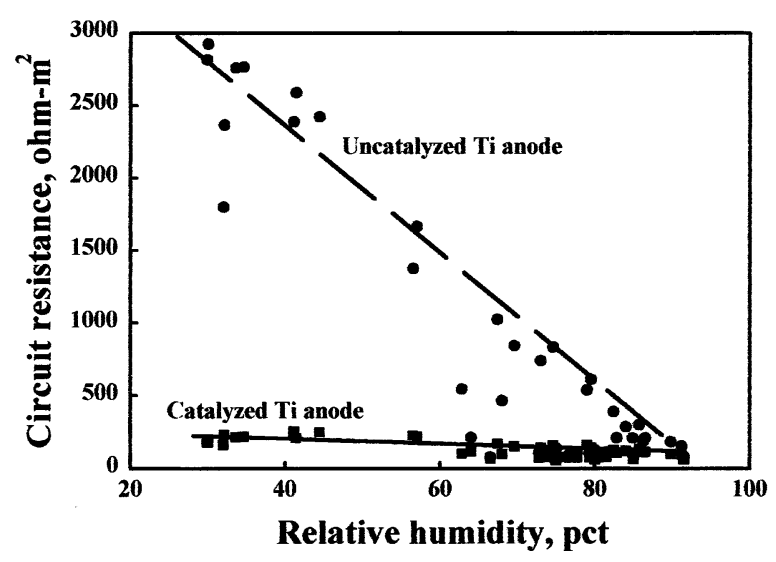

Fig. 2. Circuit resistance of catalyzed and uncatalyzed thermalsprayed titanium anodes in ICCP service as a function of relative humidity.

from the environment to maintain the anode reaction. Field operation of the anode on zone 14 of the Depoe Bay Bridge (OR) has been stable for 7 years.

\subsubsection{Solvent-based Carbon Paint Anode}

In theory, the solvent-based carbon paint anode is consumable. However, acidification of the interface in highchloride environments such as the Oregon coast can change the kinetics from carbon consumption to chloride oxidation, producing hypochlorous acid and its gaseous analogue chlorine monoxide. ${ }^{8)}$ In this way, the carbon anode behaves in ways similar to the TS titanium anode, supporting anode reactions utilizing reactants originating in the coastal environment. The carbon paint anode is the secondary anode in a system that uses a Pt-clad niobium wire primary anode. It is applied at a dry film thickness of $0.38-0.50 \mathrm{~mm}(15-20$ mil). It is typically topcoated with a water-based nonconductive acrylic paint. Chloride profiles for the underlying concrete suggest that chloride is extracted from the cover concrete during anode operation and the reaction products are removed in precipitation washing the anode surface or by gas evolution. Rebar depolarization measurements over 15 years meet the $100 \mathrm{mV}$ depolarization standard and show the rebar is adequately protected by the carbon paint anode. At 15 years service the average anode bond strength was $0.50 \mathrm{MPa}$ (73 psi), anode consumption appeared low, and the anode-concrete interface remained in good condition.

\subsection{SACP Anodes}

SACP systems are simpler and less costly to install than ICCP systems, and operate immediately and continuously since they require no external power source and rely solely on the galvanic couple between the anode and rebar. Some state DOT's have applied TS anodes over the exposed rebar to form the couple. While this is the least expensive installation and may be perfectly adequate for short-term service (5-10 years), CP system performance cannot be monitored if the anode is not isolated from the rebar so that current output of the anode and depolarization of the rebar can be measured.

\subsubsection{TS Zinc Anode}

This is the same anode as used in ICCP service. Current

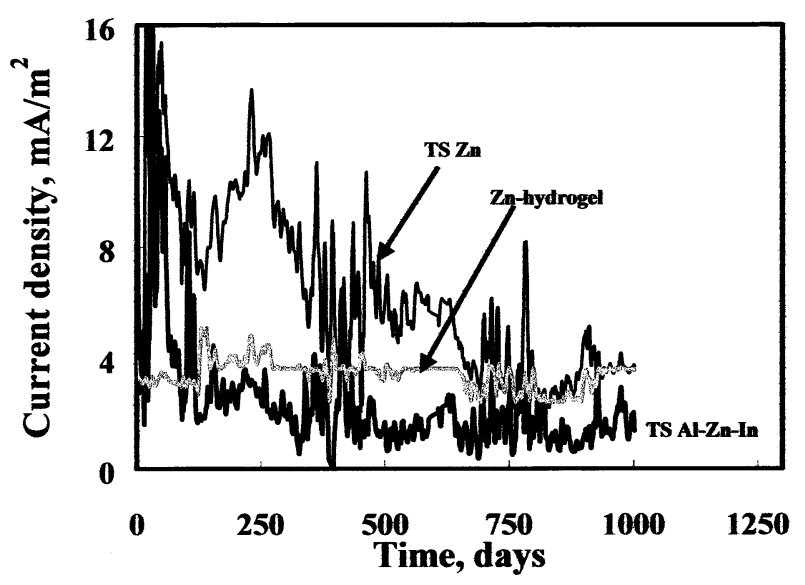

Fig. 3. Current output over 3 years for SACP anodes on the Cape Perpetua Viaduct.

output on the Cape Perpetua Viaduct has trended downward over 5 years of service as zinc mineral anode reaction products have accumulated at the anode-concrete interface, starting out at $10-15 \mathrm{~mA} / \mathrm{m}^{2}$ and decreasing to about 2 $\mathrm{mA} / \mathrm{m}^{2}$, Fig. 3. The initial current output is much higher than necessary and, by adjusting it downward, the life of the anode would be extend. Seasonal variations in current output occur, just as with TS zinc ICCP anodes, as a consequence of changing moisture levels at the anode-concrete interface. At 5 years, current levels continue to provide adequate protection of the rebar.

\subsubsection{TS AlZnIn Anode}

The TS 88Al12Zn0.2In alloy anode is applied by the TS process using a $3.2 \mathrm{~mm}(1 / 8 \mathrm{inch})$ diameter cored wire. $\left.{ }^{7,12}\right)$ The wire consists of an aluminum sheath containing a $\mathrm{Zn}$ In powder mixture that yields the desired alloy composition when melted. TS application is the same as for aluminum. Anode thickness is about $0.18 \mathrm{~mm}(7 \mathrm{mil})$. The anode used in Oregon contained $0.08 \mathrm{wt} \% \mathrm{Cu}$; current wire contains less than $0.01 \mathrm{wt} \% \mathrm{Cu}$. The anode reaction includes oxidation of both zinc and aluminum. In accelerated laboratory studies the anode bond strength decreased rapidly with service, disbonding in as little as 4 years service at typical Oregon DOT current densities for coastal bridges. Current output on the Cape Perpetua Viaduct has trended downward over 5 years service as zinc and aluminum mineral anode reaction products have accumulated at the anode-concrete interface, starting at $5-8 \mathrm{~mA} / \mathrm{m}^{2}$ and decreasing to $1-1.5 \mathrm{~mA} / \mathrm{m}^{2}$, Fig. 3. Self-corrosion of the anode is high in areas of the viaduct that remain moist for extended periods. After 5 years service, anode disbondment is significant, involving a growing fraction of the $\mathrm{CP}$ zone.

\subsubsection{Zinc-hydrogel Anode}

The zinc hydrogel anode is a $0.25 \mathrm{~mm}(10 \mathrm{mil})$ thick, non-porous zinc foil, backed with a conductive, pressuresensitive adhesive. ${ }^{712}$ The adhesive is a hygroscopic acrylate polymer $0.75 \mathrm{~mm}(30 \mathrm{mil})$ thick containing sulfonic acid. It is charged with lithium chloride to form an electrolyte at the anode-concrete interface. The anode comes in rolls with a removable plastic film backing. The backing is removed and the zinc rolled onto the concrete with a hard rubber or wood roller to press the adhesive into the con- 
crete. The edges of the anode are sealed with silicone rubber caulking to prevent water from reaching the adhesive and causing it to swell. Like TS zinc, the anode is consumable, but the weak sulfonic acid in the adhesive buffers acidity resulting in little change in $\mathrm{pH}$ at the anode-concrete interface. The initial bond strength of the anode is $0.1 \mathrm{MPa}$ (15 psi). Circuit resistance varies little with service and is insensitive to changes in the environment. Current output on the Cape Perpetua Viaduct has remained constant over 5 years at about $3.5 \mathrm{~mA} / \mathrm{m}^{2}$, Fig. 3. Rebar depolarization values are consistently in the range $150-200 \mathrm{mV}$, indicating the rebar is protected.

\section{New RC Bridges in Severe Environments}

\subsection{Epoxy-coated Reinforcing Bar}

Fusion-bonded ECR has been used in approximately $20000 \mathrm{RC}$ bridge decks and 100000 total structures in the US. Superior performance is achieved in bridge decks when both mats are ECR compared to decks using only a top ECR mat. The use of an adequate, good quality, concrete cover; finishing and curing of the concrete; and the proper manufacturing and handling of ECR complement the use of ECR in providing effective corrosion protection for concrete bridge decks. American Association of State Highway and Transportation Officials (AASHTO) and American Society for Testing and Materials (ASTM) specifications continue to evolve to improve the performance of ECR in $\mathrm{RC}$ bridges. Compared to black steel, the cost premium in new construction using ECR in both mats of bridge decks is about $1 \%$.

ECR was introduced in the mid-1970s as a means of extending the useful life of highway structures by minimizing concrete deterioration caused by corrosion of the reinforcing steel. The epoxy coating is intended to prevent moisture and chlorides from reaching the surface of the reinforcing steel and reacting with the steel. It also serves to electrically isolate the steel by minimizing the flow of corrosion current. Since introduction in the late 1970s, the highway industry has widely used epoxy-coating (thermoset) as the preferred protective system for steel reinforcing bars in bridge decks due to ECR's excellent performance in resisting corrosion and avoiding subsequent deterioration of the concrete. $^{13)}$

\subsubsection{Performance}

When used in substructures, the same type of epoxycoated rebar did not perform as expected in a few bridges exposed to a severely corrosive environment. Such is the case with a number of segmental concrete bridges located in the Florida Keys. Significant premature corrosion of ECR was observed in substructure members of these bridges when they were only 6-9 years old. These members are subjected to salt spray in the splash zone where the usual wetting/drying cycles, and high water and air temperatures produce a very corrosive environment. The deterioration observed on the Florida Key bridges and on some other bridges located in harsh environments has raised questions about ECR as a durable corrosion-protection system. The following summarizes the results of Smith and Virmani. ${ }^{14)}$

In response to reports of poor performance of ECR, most notably the bridges in the Florida Keys, several State DOT agencies (based on the recommendation of the FHWA) evaluated the performance of ECR in existing bridge decks. The bridge decks and other structures were evaluated in the field for cracking, delamination, and spalling. Overall, the structures were generally found to be in good condition. Concrete deterioration was generally in isolated areas and often not related to corrosion of the ECR.

The chloride concentration at the rebar level for most of the bridges examined was at or above the chloride corrosion initiation threshold for black steel; in some bridges concentrations were still below the threshold level. Chloride concentrations above $3 \mathrm{~kg} / \mathrm{m}^{3}$, which is above the threshold level for black steel, were measured for several bridges.

In several instances, ECR segments were extracted from cores to determine the condition of the steel surface under the coating. Of the 202 ECR segments extracted from bridge decks approximately $20 \%$ exhibited some evidence of corrosion, while the majority ( $80 \%$ ) exhibited no corrosion. For the segments where corrosion was noted, the corrosion may have been present at the time of construction since chloride contents at the time of the evaluation were below the corrosion initiation threshold. Only four ECR segments $(2 \%)$ were reported as having experienced significant corrosion. The areas of corrosion were typically at locations of visible coating holidays or bare areas on the coated rebar. The more heavily corroded ECR segments were also from locations of relatively shallow concrete cover with high chloride concentrations.

Some ECR segments extracted from the cores were examined for coating adhesion. The extent of reduction in coating adhesion (compared to virgin) varied and was found in both corroded and non-corroded areas. Visible holidays were generally present on ECR segments that experienced reduction in adhesion. In most cases, the coating remained bonded to the steel surface. Typically, a coating that has significant reduction in adhesion has a higher likelihood for corrosion if environmental conditions will support corrosion.

California reported adhesion reduction on 12 of 32 ECR segments in both corroded and non-corroded areas. Except for one segment, visible holidays were present on all ECR segments that experienced adhesion loss. The extent of coating disbondment varied from 3 to $100 \%$ of the rebar surface with six segments having coating disbondment of more than $75 \%$ of their surface.

The overall condition of the bridge decks was considered to be good. Even though deck cracking was prevalent, it did not appear to be corrosion-related. Very few of the decks had any delamination or spalling. Most of the delamination was not associated with ECR. The "maximum" extent of delamination reported was less than $1 \%$ of the deck area. The use of ECR has reduced, if not completely eliminated, the deterioration of deck concrete resulting from corrosion of reinforcing steel. A comparison of the performance of ECR in decks with only the top mat of reinforcing steel epoxy-coated and decks with both the top and bottom mat of reinforcing steel epoxy-coated suggests superior performance when both mats are epoxy-coated. The use of an adequate, good quality, concrete cover; finishing and curing of the concrete; and the proper manufacturing and handling of 
Table 4. Materials costs for recent coastal bridge projects in Oregon using stainless steel reinforcing bar in corrosion critical areas and black iron bar.

\begin{tabular}{|c|c|c|c|}
\hline Project & Brush Creek & Smith River $^{\mathrm{a}}$ & Haynes Inlet \\
\hline Year completed & 1998 & 1999 & 2003 \\
\hline \multicolumn{4}{|c|}{ Stainless steel bar } \\
\hline Uses & deck, beams & prestressed girders & deck, beams \\
\hline Alloy & $316 \mathrm{~N}$ & $316 \mathrm{~N}$ & 2205 \\
\hline Yield strength, MPa (ksi) & $414(60)$ & $414(60)$ & $517(75)$ \\
\hline Unit price, $\$ / \mathbf{k g}(\$ / \mathrm{lb})$ & $\$ 7.88(\$ 3.58)$ & $\$ 262.47 /$ girder meter & $\$ 5.02(\$ 2.28)$ \\
\hline Quantity, kg & 42,270 & 2713 girder meters & 320,000 \\
\hline Total stainless cost $^{b}$ & $\$ 333,660$ & $\$ 712,080$ & $\$ 1,610,000$ \\
\hline Equivalent black steel bar cost ${ }^{\text {b }}$ & $\$ 107,790$ & not available & $\$ 486,400$ \\
\hline \multicolumn{4}{|c|}{ Black steel bar } \\
\hline Unit price, \$/kg (\$/lb) & $\$ 2.55$ & not available & $\$ 1.52(\$ 0.69)$ \\
\hline Quantity, kg & 69,550 & not available & 600,000 \\
\hline Total black steel bar cost ${ }^{b}$ & $\$ 187,020$ & $\$ 390,900$ & $\$ 900,000$ \\
\hline \multicolumn{4}{|c|}{ Project summary } \\
\hline Total project cost & $\$ 2,259,380$ & $\$ 8,565,080$ & $\$ 11,055,400$ \\
\hline Stainless cost as \% of project cost & $14.8 \%$ & $8.3 \%$ & $14.5 \%$ \\
\hline $\begin{array}{l}\text { Stainless cost premium over black } \\
\text { steel bar as \% of project cost }\end{array}$ & $10.0 \%$ & not available & $10.2 \%$ \\
\hline
\end{tabular}

ECR complement the use of ECR in providing effective corrosion protection for concrete bridge decks.

\subsubsection{Specifications}

With continued updates in the AASHTO and ASTM specifications for epoxy-coated rebar, this corrosion protection system will continue to improve. The specifications involve all aspects of the fabrication of epoxy-coated rebar, including the following: certification of coating plant; proper storage of coating powder at the plants; restrictions on surface imperfections on the bars; removal of dust and salt from the surface of the bars prior to coating; and better quality control of thickness, continuity, flexibility, adhesion. In addition, requirements related to job-site storage and handling of the coated bars have also been established. All of these result in improved performance of epoxy-coated rebar and more durable new concrete structures.

\subsection{Stainless Steel Reinforcing Bar}

Austenitic and duplex stainless steels are used in Oregon to provide an acceptable combination of corrosion resistance, yield strength, availability, cost, and service life for reinforcing bar in new coastal bridge construction. Five state DOT's, the Ontario (Canada) Ministry of Transportation, and the Garden State Parkway Authority (NJ) have used solid stainless steel rebar in bridge construction. Fourteen other state DOT's are using stainless steel clad rebar under the FHWA Innovative Bridge Research and Construction Program to reduce corrosion damage risks. Oregon DOT decided the 10-20 year benefit that may be realized from using ECR is insufficient to offset expected inspection, maintenance and repair costs, and the barrier ECR poses to the application of cathodic protection late in a structures life. Oregon DOT's goal is to build economical coastal bridges with a service life of $120+$ years, i.e., roughly twice that of present Oregon coastal RC bridges.

\subsubsection{Performance}

Stainless steel is specified for use in corrosion critical areas, such as decks, beams and prestressed girders. It is used in combination with new grades of concrete that retard penetration by chloride ions while applying updated standards for concrete cover. Service life of bridges built in this way is improved in five distinct ways. Chloride penetration rates into the concrete are substantially reduced. Cover concrete is increased for the severest service further delaying the exposure of rebar to chloride. Chloride corrosion initiation thresholds are an order of magnitude higher for stainless steels than black bar and ECR, requiring high chloride concentrations in the concrete to initiate corrosion on stainless steels. ${ }^{4,15)}$ Stainless steel corrosion rates are orders of magnitude lower than for black bar, delaying buildup of steel corrosion products to a level that would cause concrete to crack. ${ }^{4}$ Finally, stainless rebar is made electrically continuous to permit future application of CP if needed, a reasonable precaution when applying new technology. Cost analysis of three Oregon coastal bridge projects shows stainless steel rebar can be used in new coastal bridge construction at a premium of about $10 \%$ relative to total project cost, Table 4.

Black steel bar and epoxy-coated black steel bar have a chloride corrosion initiation threshold of $0.74 \mathrm{~kg} \mathrm{Cl} / \mathrm{m}^{3}$ $\left(1.25 \mathrm{lb} \mathrm{Cl} / \mathrm{yd}^{3}\right) .{ }^{4)}$ Type 304 stainless steel has a chloride threshold, when isolated from galvanic couples with black bar, of about $11 \mathrm{kgCl} / \mathrm{m}^{3}\left(19 \mathrm{lb} \mathrm{Cl} / \mathrm{yd}^{3}\right)$, and the threshold for Type 316 stainless is about $\left.18 \mathrm{~kg} \mathrm{Cl} / \mathrm{m}^{3}\left(31 \mathrm{lb} \mathrm{Cl} / \mathrm{yd}^{3}\right){ }^{4}\right)$ Other possible stainless bar compositions, considered by Oregon DOT and representing suitable alternatives to Type 316LN stainless, include Nitronic 50 and duplex alloy 2205. Inspection of chloride concentrations in 40-70 year old RC bridges in severely corrosive coastal Oregon environments has failed to identify any case where chloride concentrations, even at the surface of the concrete, reached the corrosion initiation threshold for Type 316 stainless. ${ }^{12)}$ Cases were identified, however, that exceeded the threshold for Type 304 stainless. This suggests a low likelihood that corrosion would initiate on 316LN stainless steel.

Black steel bar can corrode in chloride contaminated concrete at rates of $11-23 \mu \mathrm{m} / \mathrm{y}(0.46-0.91 \mathrm{mil} / \mathrm{y}) .{ }^{16)}$ In contrast, stainless steels corrode at rates several orders of magnitude less, i.e., $0.05 \mu \mathrm{m} / \mathrm{y}(0.002 \mathrm{mil} / \mathrm{y}) .{ }^{4)}$ If corrosion 
were to initiate, stainless steel reinforcing bar would take far longer to build up sufficient corrosion products to initiate cracking of the concrete.

While long-term benefits and problems from using stainless steel reinforcing bar in coastal bridge construction will not be known with certainty for generations, there are examples that suggest the choice is sound when the goal is $120+$ year bridges. The Port of Progreso Pier in Yucatan, Mexico, built using Type 304 stainless reinforcing bar, has been in service for over 60 years in a hot, humid, and salty environment, and has required virtually no maintenance because of corrosion damage. ${ }^{17)}$

Austenitic and duplex stainless steels (Type 316, Nitronic 50, and 2205) appear to offer an acceptable combination of corrosion resistance, mechanical properties (yield strength), availability, cost, and service life for reinforcing bar in coastal bridge applications. The higher strength of the duplex 2205 makes this alloy an attractive standard for bridge construction. Oregon DOT presently specifies solid, as opposed to clad, stainless bar. Research is need to determine whether the performance of clad stainless bar can achieve the performance desired by bridge owners such as Oregon DOT without introducing the risks attendant with using a coating.

\subsubsection{Specifications}

The specification for stainless steel is based on yield strength, corrosion threshold, and corrosion rate. It is an "allowable" specification in that it allows a contractor to choose 316 LN, duplex 2205 alloy, or Nitronic 50. Oregon DOT worked with the FHWA to ensure support for both the concept of $120+$ year service life through the use of stainless steel reinforcing bar and the format of the Oregon DOT "allowable" specification for use with Federal aid funding.

At a cost of \$21 million total, Oregon DOT has completed two bridge projects using stainless steel reinforcing bar and a third is nearing completion, Table 4 . The latter project takes advantage of the ability of mills to work the duplex alloy to produce higher yield strength bar so that less steel is required. In the next six years, two additional bridge replacement projects will use stainless steel reinforcement in corrosion critical areas. Stainless steel bar is used in deck, beams, and precast girders. Black steel bar is used in compressive members such as columns and arches. The black bar is used with adequate concrete cover and is electrically isolated from the stainless bar. The new grades of concrete substantially reduce long-term exposure of the black bar to chloride ion and CP can easily and effectively be applied later if needed.

Costs are given individually in Table 4 for the stainless steel and black steel bar used in these projects. Total steel prices are simply the unit price times the quantity. The cost of black bar equivalent to the stainless steel used in corrosion critical areas is given as a separate entry. While stainless steel bar costs a factor of three or more than black bar, use of stainless steel in the projects raised total project costs only $10 \%$ compared to the equivalent quantity of black bar. Use of stainless steel is expected to yield a $120+$ year bridge life while substantially reducing inspection costs, eliminating most maintenance and repair costs, and eliminating the need for deck replacement during the bridge life.

\subsection{High Performance Concrete}

The type and quality of concrete can provide significant protection of reinforcing steel. Oregon and other states are using microsilica and fly ash in concrete to reduce permeability of the concrete. These pozzalanic materials greatly reduce the remaining pore water in concrete, which consequently reduces the ability of chlorides to penetrate the concrete to the steel and the availability of oxygen for corrosion. They also enable the concrete to withstand much higher compressive forces. The FHWA has been advocating the use of these newer grades of high durability or high performance concretes for some time. With regard to corrosion, microsilica concrete (silica-fume concrete) lowers the effective chloride ion diffusion coefficients greatly, retarding salt transport into the concrete, steepening the chloride profile in the cover concrete, and extending substantially the time for chloride to reach the reinforcing bar.

Oregon DOT has been using microsilica concrete $(4 \%$ microsilica maximum plus fly ash) in coastal bridge construction since 1996 for compressive members of structures where the corrosion risk is not high enough to justify stainless steel reinforcing bar. The minimum specified concrete cover is $38 \mathrm{~mm}$ ( 1.5 inches), a typical cover value is $51 \mathrm{~mm}$ ( 2 inches) and, in particularly harsh environments, $76 \mathrm{~mm}$ ( 3 inches) cover is specified. These cover specifications apply to all reinforcement, including shear stirrups, deck undersides and the bottom of beams and contribute to the $120+$ year bridge life expected when using stainless bar. Use of microsilica concrete throughout the structure, including the deck, has the added advantage of excellent abrasion resistance.

\section{Steel Bridge Coatings Systems for Severe Environ- ments}

Paints are the most widely used material for protecting steel structures from corrosion damage. They create a barrier between the steel and corrodants that can last without maintenance in mild environments up to 20 years, and substantially shorter times in severely corrosive environments. Metalizing with zinc, aluminum, and their alloys produces a long-lasting protective coating that is a barrier to corrodants and also provides a degree of galvanic protection in areas of coatings damage and wear. Metallized coatings may be used as the bare sprayed metal, or as the sprayed metal plus sealer, or as the sprayed metal and sealer plus a paint topcoat. The relatively thick bare metal coating has the longest life-to-first-maintenance. Sealing the coating with no subsequent maintenance of the sealer yields the longest coating service life, the lowest life-cycle cost, and the most economical coating system. Topcoating is used in circumstances for aesthetic purposes, particularly in public structures such as bridges. The high spray and deposit rates, and portability of today's equipment make metalizing competitive with painting on both a first cost and life-cycle basis.

The metalized coating system consists of three essential steps. These steps are surface preparation (cleaning and profiling the steel), thermal-spraying the metal coating, and sealing the coating. The detailed requirements for each of these steps are covered in SSPC-CS 23.00 ${ }^{18)}$ and ANSI/ 
Table 5. Estimated unsealed thermal-sprayed $\mathrm{Zn}$ and $85 \mathrm{Zn}-15 \mathrm{Al}$ alloy coating thickness required for a specific service life. ${ }^{19)}$

\begin{tabular}{c|c|c|c|c}
\hline \multirow{2}{*}{ Environment } & \multicolumn{4}{|c}{ Coating thickness required for specific service life, $\mu$ m (mil) } \\
\cline { 2 - 5 } & $\mathbf{5 - 1 0}$ yrs & $\mathbf{1 0 - 2 0}$ yrs & $\mathbf{2 0 - 4 0}$ yrs & $>$ 40 yrs \\
\hline Rural atmosphere & - & $75-125(3-5)$ & $150-200(6-8)$ & $250-300(10-12)$ \\
\hline Industrial atmosphere & - & $150-200(6-8)$ & $300-375(12-15)$ & $350-400(14-16)$ \\
\hline Marine atmosphere & - & $250-300(10-12)$ & $300-375(12-15)$ & $350-400(14-16)$ \\
\hline Fresh water & $150-200(6-8)$ & $250-300(10-12)$ & $300-375(12-15)$ & - \\
\hline Potable water & - & $250-300(10-12)$ & $300-375(12-15)$ & - \\
\hline Sea water immersion & $250-300(10-12)$ & $350-400(14-16)$ & - & - \\
\hline
\end{tabular}

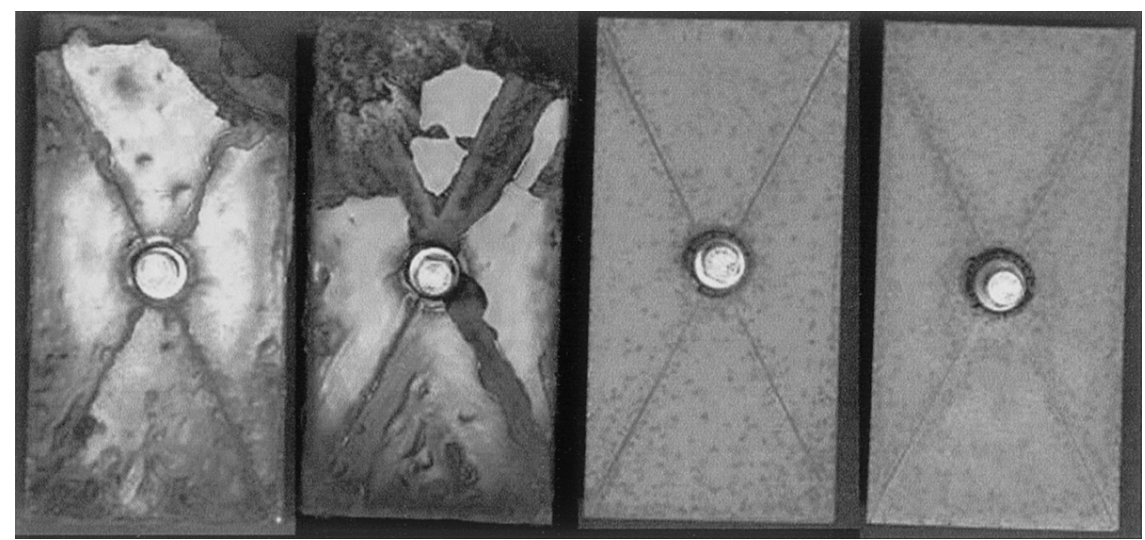

Fig. 4. Skyward side paint samples boldly exposed for 6 years at the Yaquina Bay Bridge (L to R): $30^{\circ}$ bridge paint, $90^{\circ}$ bridge paint, $30^{\circ}$ sealed thermal-sprayed $\mathrm{Al}, 90^{\circ}$ sealed thermal sprayed $\mathrm{Al}$.

AWS 2.18-93. ${ }^{19)}$

\subsection{Surface Preparation}

Surface preparation for metalizing begins with blast cleaning to SSPC-SP 10 for atmospheric service or SSPCSP5 for all immersion and marine service. ${ }^{18)}$ The blasted surface must have an angular profile, usually in the range of 0.10 to $0.16 \mathrm{~mm}$ (2.5 to $4.0 \mathrm{mil})$ deep. This profile is the anchor tooth pattern to which the particles of sprayed metal adhere to form the coating's mechanical bond. There are several practical matters to consider with regard to the surface preparation, such as the type and size of grit, holding period or the time between blast cleaning and metalizing, and rust bloom.

\subsection{Thermal Spraying}

Three types of wires are usually used to coat structural steel. These are pure zinc (99.99\%), pure aluminum (99.0\%), and an alloy of these two metals, $85 \%$ zinc $-15 \%$ aluminum $(85 / 15)$, in either 3.2 or $4.8 \mathrm{~mm}(1 / 8$ or $3 / 16$ inch) wire diameter. ${ }^{20}$ ) Pure zinc and the $85 / 15$ alloy are commonly used to coat bridge steel in the U.S. To date, little aluminum has been sprayed on bridge steel. Zinc is somewhat easier to spray than either of the other two wires. Zinc is said to be "more forgiving" of surface preparation. Zinc is preferred in more alkaline conditions. Aluminum on metalized steel parts tends to react when exposed to freshly poured (alkaline) concrete.

Typical operating conditions for the twin-wire arc-spray process and spray rates are given in Table 3 for zinc wire. In most cases, the metal coatings made using these alloys will protect steel structures for years. The coatings conform well to the roughened steel surface produced by sandblasting and will bridge or fill rougher areas on the steel surface. Porosity is typical of the coatings. Table 5 gives unsealed $\mathrm{Zn}$ and $85 \mathrm{Zn}-15 \mathrm{Al}(85-15)$ thermal-sprayed coatings thick- nesses required according to the American Welding Society for specific service lives in a variety of atmospheric and immersion service. ${ }^{19)}$ A $350-400 \mu \mathrm{m}$ (14-16 mil) thick coating is adequate to provide greater than 40 years service on a steel structure in marine atmospheres. This level of protection exceeds that delivered by paint systems alone and will substantially reduce life-cycle costs for coating maintenance, repair and application. ${ }^{21,22)}$

\subsection{Sealers and Topcoats}

Thermal spray coatings are naturally porous. Sealing initially preserves the metalized coating. Over time, coating corrosion products, such as aluminum or zinc oxide, selfseal the coating and the combined materials provide longer service life than either alone. The sealer allows time for the metalized coating corrosion products, and not steel corrosion products, to form and seal the coating with significant long-term benefits. Liquid sealing materials include acrylic, epoxy, phenolic, silicone, urethane, and vinyl coatings. The sealer is a low viscosity product specially formulated to flow over and be absorbed into the pores of the thermal spray coating. The sealer may be clear or pigmented. ${ }^{18)}$ When pigmented, the pigment particle size is nominally 5fineness grind. ${ }^{19)}$ Sealing improves appearance of the structure and reduces retention of dirt and contamination and makes the coating easier to clean and maintain. ${ }^{20)}$ The sealer and metal coating work synergistically, one material enhancing the performance of the other, to provide long service life at the lowest cost. ${ }^{21,22)}$

The Oregon DOT three-coat bridge paint system (zincdust-filled polyurethane primer $(75 \mu \mathrm{m} \mathrm{dft})$, moisture-cured urethane intermediate coat $(75 \mu \mathrm{m} \mathrm{dft})$, and pigmented moisture-cured urethane topcoat $(75 \mu \mathrm{m} \mathrm{dft}))$ is compared in Fig. 4 with a thermal-spray coating system consisting of thermal-sprayed aluminum (200-250 $\mu \mathrm{m})$, epoxy pre-prime sealer $(25 \mu \mathrm{m} \mathrm{dft})$, and urethane topcoat $(50 \mu \mathrm{m} \mathrm{dft})$ in ex- 
posures of mild steel panels for 6 years on the Oregon coast. The coating surfaces were deliberately damaged prior to exposure by scribing through the coating system in an Xpattern. Panels coated with the thermal-spray system was superior to the bridge paint system in all environments.

A topcoat is a full layer of paint applied over the metalized coating. ${ }^{18)}$ Sealing the metal coating prior to application of a topcoat is standard procedure. However, application to metalized coatings of "primers, undercoats and topcoats, i.e., the conventional painting systems developed for protecting bare steel", is not justified on technical or economic grounds. ${ }^{19,21)}$ Topcoating may be specified for any of the following conditions: a very acidic or very alkaline environment; the metallic coating is subject to direct attack by specific chemicals; a particular decorative finish is required; additional abrasion resistance is required; frequent saltwater spray or splash or immersion service is required; frequent fresh water spray or splash or immersion service is required, excluding potable water. ${ }^{18)}$

\subsection{Specification}

Three professional organizations in the United States have produced the specifications and other documentation needed to build the metalizing industry. These are the metalizing committees within American Welding Society (AWS), NACE International, and the Steel Structures Painting Council (SSPC). These committees have worked over the past 15-20 years to provide thorough specifications and guidance to owners and metalizing companies alike in order to facilitate the proper specification and application of metalized coatings for corrosion control. ${ }^{18-20)}$

\subsection{Advantages of Metalizing}

On an initial cost basis, metalizing is more expensive that painting. However, the actual difference between the contractor's cost to metalize and the contractor's cost to paint is minimal. Access costs, rigging, blast cleaning, blast containment are the same regardless of whether a structure is metalized or painted. Today's new thermal spray technology has brought down initial coating cost substantially. The principal advantage of metalizing is life cycle cost: "metalizing costs less than painting and repainting" over the life of a bridge. Metalized coatings last longer in severe environments than organic coatings. They contain no volatile organic compounds (VOC's). There is no curing or drying time, no minimum or maximum application temperature, and no shelf life. Metalizing is a "cold process" compared to galvanizing. There is no risk of heat distortion or weld damage; there is no limit to size or shape of the piece being metalized.

\section{Conclusions}

(1) Corrosion damage to the bridge infrastructure costs the U.S. economy proportionally more in direct and indirect costs than damage in many other sectors of the economy.

(2) Conductive coating anodes can be an effective strategy for providing CP to existing RC bridges. In Oregon, TS zinc, catalyzed TS titanium, and solvent-based carbon paint anodes have been successfully applied in continuing service up to 15 years in ICCP systems. Zinc hydrogel and, to a lesser extent, TS zinc have performed well in continuing service of 5 years in SACP systems.

(3) ECR continues to improve as an economical and effective means for providing corrosion protection and added service life to RC structures, particularly bridge decks. Its use requires adherence to standards of production, quality control, and job-site handling.

(4) Austenitic and duplex stainless steel rebar can provide resistance to severely corrosive environments, yield strength, availability, cost and service life for construction of bridges with a $120+$ year service life at a cost premium of only $10 \%$ relative to total project cost.

(5) Thermal-sprayed $\mathrm{Zn}, \mathrm{Al}$, and $\mathrm{Zn}-\mathrm{Al}$ alloys combined where necessary with a sealer provide the basis of economical 40 year life protective coatings systems for steel bridges exposed to severe environments. The standards and specifications for this technology are well established.

\section{Nomenclature}

CP : Cathodic protection

ECR: Epoxy-coated rebar

RC: Reinforced concrete

TS : Thermal-spray(ed)

ICCP : Impressed-current cathodic protection

SACP : Sacrificial anode cathodic protection

Electrochemical age: The cumulative charge that passes across the anode-concrete interface, expressed as a charge density in $\mathrm{kC} / \mathrm{m}^{2}$

\section{REFERENCES}

1) H. O. Bonstedt: Concrete International, 20 (1998) No. 10, 65.

2) The Status of the Nation's Highway Bridges: Highway Bridge Replacement and Rehabilitation Program (HBRRP) and National Bridge Inventory, Thirteenth Report to the United States Congress, FHWA, USDOT, Washington DC, (1997).

3) G. H. Koch, M. H. P. Brongers, N. G. Thompson, Y. P. Virmani and J. H. Payer: Report No. FHWA-RD-01-156, FHWA, USDOT, Washington DC, (2002), 773; also Y. P. Virmani: Tech Brief, FHWARD-01-157, FHWA, USDOT, Washington DC, (2002), 17.

4) D. B. McDonald, D. W. Pfeifer and M. R. Sherman: Report No. FHWA-RD-98-153, FHWA, USDOT, Washington DC, (1998).

5) B. S. Covino, Jr., S. D. Cramer, S. J. Bullard, G. R. Holcomb, J. H. Russell, W. K. Collins, H. M. Laylor and C. B. Cryer: FHWAOR-RD-02-10; FHWA, USDOT, Washington DC, and Oregon Department of Transportation, Salem, OR, (2002).

6) S. D. Cramer, B. S. Covino, Jr., G. R. Holcomb, S. J. Bullard, W. K. Collins, R. D. Govier, R. D. Wilson and H. M. Laylor: J Therm. Spray Technol., 8 (1999), No. 7, 133.

7) S. J. Bullard, B. S. Covino, Jr., S. D. Cramer, G. R. Holcomb, J. H. Russell, J. E. Bennett, C. B. Cryer and H. M. Laylor: Paper no. 28, Proc. 14th Int. Corrosion Cong., CorrISA, Kelvin, South Africa, (1999), 10.

8) S. D. Cramer, S. J. Bullard, B. S. Covino, Jr., G. R. Holcomb, J. H. Russell, C. B. Cryer and H. M. Laylor: Paper no. 02265, Corrosion/2002, NACE International, Houston, TX, (2002).

9) ODOT: Special Provisions for Highway Construction Rogue River (Gold Beach) Rehabilitation and Cathodic Protection, Contract No. 12549, Construction Contracting, Oregon Department of Transportation, Salem, OR, (2001).

10) F. Rogers: Int. Thermal Spray Conf. 2000, ed. by C. C. Berndt, ASM International, Materials Park, OH, (2000), 5.

11) G. R. Holcomb, B. S. Covino, Jr., J. H. Russell, S. J. Bullard, S. D. Cramer, W. K. Collins, J. E. Bennett and H. M. Laylor: Corrosion, 56 (2000), No. 11, 1140.

12) S. D. Cramer, B. S. Covino, Jr., S. J. Bullard, G. R. Holcomb, J. H. Russell, F. J. Nelson, H. M. Laylor and S. M. Soltesz: Cem. Concr. Compos., 24 (2002), 101. 
13) Y. P. Virmani: FHWA-RD-96-092, Turner-Fairbank Highway Research Center, FHWA, USDOT, Mclean, VA, (1997).

14) J. L. Smith and Y. P. Virmani: Public Roads, 60 (1996) No. 2, 6.

15) M. J. Hurley and J. R. Scully: Paper no. 02224, Corrosion/2002, NACE International, Houston, TX, (2002).

16) M. G. Stewart and D. V. Rosowsky: J Infrastructure Systems, 4, (1998), No. 4, 146.

17) Ramboll Consulting Engineers. Pier in Progreso Mexico Inspection Report-Evaluation of Stainless Steel Reinforcement, Arminox, Viborg, Denmark, (1999).

18) Interim Specification for the Application of Thermal Spray Coatings (Metalizing) of Aluminum, Zinc and Their Alloys and Composites for the Corrosion Protection of Steel, SSPC CS 23.00(I); SSPC
(Steel Structures Painting Council), Pittsburgh, PA, (2000).

19) Guide for the Protection of Steel with Thermal Sprayed Coatings of Aluminum and Zinc and Their Alloys and Composites, ANSI/AWS C2.18; American Welding Society, Miami FL; American National Standards Institute, Washington DC, (1993).

20) Specification for Thermal Spray Feedstock Solid and Composite Wire and Ceramic Wire and Ceramic Rods, AWS C2.25/C2.25M; American Welding Society, Miami, FL, (2001).

21) Code of Practice for Protective Coating of Iron and Steel Structures against Corrosion, BS 5493, British Standards Institution, London, (1977), 21.

22) R. A. Kogler, J. P. Ault and C. L. Farschon: FHWA-RD-96-058, FHWA, USDOT, Washington DC, (1997). 